\title{
Caracterização agronômica e pós-colheita das bananeiras 'Maravilha' e 'Preciosa' no Submédio do Vale São Francisco'
}

\author{
Marlon Jocimar Rodrigues da Silva ${ }^{2 *}$, Paulo Ricardo Rodrigues de Jesus ${ }^{3}$, João Marcos Chagas dos Anjos ${ }^{3}$, \\ Marilza Machado ${ }^{4}$, Valtemir Gonçalves Ribeiro
}

10.1590/0034-737X201663010007

\begin{abstract}
RESUMO
A caracterização e a avaliação de novos genótipos de bananeira é uma etapa importante, tanto para os programas de melhoramento genético quanto para a indicação aos produtores. Assim, o objetivo desta pesquisa foi avaliar a produção e a qualidade de frutos, em pós-colheita, das bananeiras 'Maravilha' e 'Preciosa', no primeiro e segundo ciclo de produção, cultivadas no Submédio do Vale do São Francisco. As mudas, produzidas por cultura de tecidos, foram transplantadas para o campo com seis meses de idade, cultivadas no espaçamento de $3 \times 3 \mathrm{~m}$. Nos dois ciclos avaliados, para todas as características, foi adotado o delineamento experimental inteiramente casualizado, com dois tratamentos (cultivares), dez repetições e duas plantas úteis por parcela, com bordadura externa ao ensaio. Foram avaliadas as seguintes variáveis: ciclo de produção (dias entre plantio e colheita), altura de planta, perímetro do pseudocaule, número de folhas adultas, massa da matéria fresca do cacho, número de pencas e de frutos por cacho, massa da matéria fresca da segunda penca; número, comprimento e diâmetro de frutos da segunda penca, relação polpa/casca, firmeza, pH, teor de sólidos solúveis (SS), acidez titulável (AT) e relação SS/AT. O cultivar 'Maravilha' apresentou características de planta e de produção superiores às do 'Preciosa'; quanto às características físicoquímicas, o 'Preciosa' apresentou frutos com maiores teores de açúcares, todavia, menores em tamanho; para as demais características, os dois cultivares apresentaram comportamentos semelhantes entre si, no primeiro e no segundo ciclo de produção.
\end{abstract}

Palavras-chave: Musa sp., desempenho agronômico, características físico-químicas.

\section{ABSTRACT}

\section{Agronomic characterization and post-harvest of 'Maravilha' and 'Preciosa' bananas in Sub-middle São Francisco Valley}

The characterization and evaluation of new genotypes bananas is an important step both for breeding programs and for nomination to producers. The aim of this study was to evaluate the yield and fruit quality post-harvest of 'Maravilha' and 'Preciosa' bananas in the first and second production cycles, grown in Sub-middle São Francisco Valley. The seedlings produced by tissue culture, were transplanted to the field after six month old, cultivated in the spacing of $3 \times 3 \mathrm{~m}$. Both two cycles, for all characteristics was adopted a completely randomized design with two treatments (cultivars), 10 replicates and two plants per plot, with external borders. The following variables were evaluated: production cycle (days between planting and harvesting), plant height, pseudostem perimeter, number of adult leaves, bunch fresh mass, number of cluster and fruits per bunch, fresh mass of the second cluster; number,

Submetido em 18/03/2014 e aprovado em 21/09/2015

${ }^{1}$ Apoio financeiro: Fundação de Amparo à Pesquisa do Estado da Bahia.

2Universidade Estadual Paulista, Faculdade de Ciências Agronômicas, Botucatu, São Paulo, Brasil. marlonjocimar@gmail.com

Universidade do Estado da Bahia, Departamento de Tecnologia e Ciências Sociais, Juazeiro, Bahia, Brasil. eng.p.ricardo@gmail.com; jmanjos@hotmail.com

${ }^{4}$ Universidade Estadual Paulista, Faculdade de Ciências Agronômicas, Botucatu, São Paulo, Brasil. marilzabio@gmail.com

${ }^{5}$ Universidade do Estado da Bahia, Departamento de Tecnologia e Ciências Sociais, Juazeiro, Bahia, Brasil. vribeiro@uneb.com

* Autor para correspondência: marlonjocimar@gmail.com 
length and diameter of fruits of the second cluster, pulp/skin ratio, firmness, $\mathrm{pH}$, soluble solids (SS), titratable acidity (TA) and SS/TA ratio. The 'Maravilha' banana showed plant and yield characteristics superior to 'Preciosa' banana; in the physical and chemical characteristics, the 'Preciosa' banana had fruit with higher sugar content, however, smaller size; and for other characteristics, the two cultivars showed behavior similar to each other in the first and second production cycles.

Key words: Musa sp., agronomic performance, physical-chemical characteristic.

\section{INTRODUÇÃO}

A banana é uma das frutas tropicais mais importantes, pois constitui alimento básico tanto para as populações das áreas rurais quanto das áreas urbanas. Especialmente no Semiárido brasileiro, a bananicultura contribui para a melhoria da economia e para a inclusão social, em áreas mais carentes (Azevedo et al., 2010).

O Submédio do Vale do São Francisco, polo de JuazeiroPetrolina, é uma região que tem sua economia centrada na fruticultura irrigada, destacando-se principalmente na produção de mangas e uvas, tanto para mercado interno quanto para exportação. No entanto, outras espécies, embora em menor proporção, são também cultivadas, a exemplo da goiabeira, do maracujazeiro, da aceroleira, além de outras fruteiras.

De modo geral, nos principais polos de produção do País predominam bananeiras tipo Prata, especificamente a 'Prata Anã'; no entanto, nas áreas irrigadas do Submédio São Francisco prevalece o cultivo da 'Pacovan' (Azevedo et al., 2010), cultivar mais aceito regionalmente. Apesar dessa expressividade, esses cultivares são susceptíveis às principais doenças endêmicas que ocorrem no Brasil, como o mal-do-Panamá, o de Sigatoka-amarela, o de Sigatoka-negra e o de Moko, os nematoides e as pragas, especialmente a broca-do-rizoma, que prejudicam o cultivo e podem ocasionar perdas de produção de até 100\% (Silva et al., 2003b; Lessa et al., 2012). Particularmente na bananeira 'Pacovan', o porte elevado torna-se também uma característica indesejável, que limita seu cultivo, principalmente em regiões com velocidade do vento elevada (Azevedo et al., 2010), como no caso das áreas irrigadas do Submédio São Francisco nos primeiros meses do ano, o que pode provocar o tombamento de bananeiras, além de dificultar a retirada de cachos na época da colheita.

Uma das estratégias para solucionar esses problemas é a obtenção de novos genótipos, resistentes a doenças e pragas, que apresentem porte baixo, sejam altamente produtivos, com frutos de boas características pós-colheita e organolépticas, apreciados pelos consumidores (Silva et al., 2003b). Para isso, importantes órgãos de pes- quisa utilizam-se do melhoramento genético para obtenção de híbridos tetraploides superiores, a partir do cruzamento de triploides tradicionais com diploides (Silva et al., 2003a). No Brasil, a Embrapa Mandioca e Fruticultura Tropical, situada em Cruz das Almas (BA) obteve, dentre outros cultivares, o 'Preciosa' (PV42-85), tetraploide do grupo AAAB, resultante do cruzamento da 'Pacovan' (AAB) com o diploide M53 (AA). Outro exemplo é o 'Maravilha' (Fhia-01), também um tetraploide do grupo AAAB, no entanto, resultante do cruzamento da 'Prata Anã' (AAB) com o diploide SH3142 (AA), criada na Fundación Hondureña de Investigación Agrícola (FHIA), Honduras, introduzido, avaliado e selecionado na Embrapa Mandioca e Fruticultura (Silva et al., 2003b).

Após a obtenção de novos genótipos, sua caracterização e a avaliação, em áreas de produção, sob diferentes condições edafoclimáticas, são etapas imprescindíveis à classificação e à utilização destes genótipos, permitindo identificar cultivares promissores, passíveis de serem integrados aos programas de melhoramento da cultura ou de serem recomendados aos agricultores (Silva et al., 2003a). Torna-se relevante, no entanto, além de avaliar as características agronômicas de um cultivar, também caracterizar os atributos de qualidade dos seus frutos (Souza et al., 2011).

Diante do exposto, o objetivo desta pesquisa foi avaliar as características de produção e a qualidade pós-colheita dos frutos das bananeiras 'Maravilha' e 'Preciosa', no primeiro e segundo ciclo de produção, cultivadas no Submédio do Vale São Francisco.

\section{MATERIAL E MÉTODOS}

O experimento foi realizado na área experimental do Departamento de Tecnologia e Ciências Sociais, da Universidade do Estado da Bahia (UNEB/DTCS), situada no município de Juazeiro, BA, Vale do São Francisco ( $9^{\circ} 25^{\prime} 43^{\prime \prime}$ S $40^{\circ} 32^{\prime} 14^{\prime \prime} \mathrm{W}$; altitude: $384 \mathrm{~m}$ ), durante os meses de abril de 2010 a dezembro de 2011.

O clima da região é classificado, segundo Köeppen, como tipo BSh, correspondente a muito quente, semiárido e com estação chuvosa limitada. Durante a condução do 
experimento, os dados meteorológicos foram obtidos pela Estação de Meteorologia do DTCS/UNEB. Os valores médios de temperaturas e umidades relativas do ar mínimas e máximas foram de 21,1 e $32,1^{\circ} \mathrm{C}$; e 45,3 e $97,1 \%$, respectivamente; a precipitação pluviométrica foi de 1,2 $\mathrm{mm} /$ dia e a velocidade do vento (medida a $2 \mathrm{~m}$ de altura em relação à superfície do solo) de $166,9 \mathrm{~km} \mathrm{dia}^{-1}$.

O solo da unidade experimental, segundo o Laboratório de Análise de Solo, Água e Calcário (LASAC), da UNEB/DTCS, na camada de 0 a $20 \mathrm{~cm}$, apresenta classe textural Franca (média), com 42,5 $\mathrm{g} \mathrm{kg}^{-1}$ de areia, 44,2 $\mathrm{g} \mathrm{kg}^{-}$ ${ }^{1}$ de silte e 13,3 $\mathrm{g} \mathrm{kg}^{-1}$ de argila. Apresenta, ainda, os seguintes atributos químicos: $\mathrm{pH}\left(\mathrm{H}_{2} \mathrm{O}\right) 5,38$; condutividade elétrica $=0,47 \mathrm{dS} \mathrm{m}^{-1} ; \mathrm{Ca}^{+2}=3,99 \mathrm{cmol}_{\mathrm{c}} \mathrm{kg}^{-1} ; \mathrm{Mg}^{+2}=3,31$ $\mathrm{cmol}_{\mathrm{c}} \mathrm{kg}^{-1} ; \mathrm{K}^{+}=0,26 \mathrm{cmol}_{\mathrm{c}} \mathrm{kg}^{-1} ; \mathrm{Na}^{+}=0,10 \mathrm{cmol}_{\mathrm{c}} \mathrm{kg}^{-1} ; \mathrm{H}^{+}+$ $\mathrm{Al}^{+3}=0,99 \mathrm{cmol} \mathrm{kg}_{\mathrm{c}} \mathrm{kg}^{-1}, \mathrm{~T}=8,65 \mathrm{cmol}_{\mathrm{c}} \mathrm{kg}^{-1} \mathrm{e} \mathrm{V}=88,55 \%$.

Os tratamentos foram os cultivares Maravilha e Preciosa, avaliados no primeiro e segundo ciclos de produção. As mudas, produzidas por cultura de tecidos, na Biofábrica de Cruz das Almas, BA, foram transplantadas para o campo quando completavam seis meses de idade, no espaçamento $3 \times 3 \mathrm{~m}$.

Durante a condução do experimento foram adotadas as seguintes práticas culturais: irrigação, controle de plantas daninhas, eliminação da inflorescência masculina e corte do pseudocaule após a colheita. O sistema de irrigação utilizado foi o localizado por microaspersão, utilizando-se microaspersores com vazão de $38 \mathrm{~L} \mathrm{~h}^{-1}$; realizandose o manejo com base na evaporação obtida no Tanque Classe "A", sendo a quantidade de água aplicada na cultura de modo a satisfazer $100 \%$ da evapotranspiração.

Nos dois ciclos, para todas as características avaliadas foi adotado o delineamento experimental inteiramente casualizado, com dois tratamentos (cultivares), dez repetições e duas plantas úteis por parcela, com bordadura externa ao ensaio.

No primeiro e segundo ciclo de produção, as características de crescimento avaliadas foram: altura de planta (m), medida do nível do solo até a roseta foliar; perímetro do pseudocaule $(\mathrm{cm})$, medido a $30 \mathrm{~cm}$ do solo com fita métrica graduada e número de folhas adultas por planta, contadas no momento da colheita. A característica duração do ciclo de produção foi avaliada por meio do cálculo da diferença entre as datas de colheita e de plantio, sendo o resultado expresso em número de dias.

Após a colheita, foram mensuradas as características de produção: massa da matéria fresca do cacho $(\mathrm{kg})$, medida com balança pendular tipo relógio; número de pencas e de frutos por cacho; massa da matéria fresca da segunda penca $(\mathrm{kg})$; número de frutos da segunda penca; comprimento de frutos da $2^{\mathrm{a}}$ penca $(\mathrm{cm})$, medido entre as duas extremidades com régua graduada; e diâmetro de frutos da $2^{\mathrm{a}}$ penca $(\mathrm{mm})$, medido na região central dos frutos.
Os cachos foram colhidos quando a primeira penca apresentou sinais de amarelecimento, ou seja, a classe 2 de maturação, de acordo com a escala de notas proposta por Von Loesecke (PBMH: PIF, 2006). Depois de colhidos, os frutos foram armazenados em forma de penca e permaneceram em condições ambientais (temperatura média de $26,8^{\circ} \mathrm{C}$ e umidade relativa média do ar de $68,5 \%$ ), até atingirem a classe 6 de maturação (fruto todo amarelo), de acordo com a escala de notas citada acima, momento em que se procedeu à separação dos cinco frutos centrais das segundas pencas, para a realização das análises físicas e químicas.

A qualidade de frutos foi analisada com base nas características: relação polpa/casca, obtida pela separação da polpa da casca, pesando-as individualmente com balança digital; firmeza, determinada com penetrômetro com ponteira de $8 \mathrm{~mm}$ de diâmetro, realizando leitura na parte central do fruto descascado, com os resultados expressos em $\mathrm{kg} \mathrm{cm}^{-2} \mathrm{e}$, em seguida, transformados para Newton (N); pH, determinado com pHmetro digital $\left(\right.$ TECNAL $^{\circledR}$ ); teor de sólidos solúveis (SS), determinado por refratometria, em refratômetro manual, sendo os resultados expressos em ${ }^{\circ}$ Brix; acidez titulável (AT), determinada por titulação com hidróxido de sódio $(\mathrm{NaOH}) ; 0,1 \mathrm{~N}$ e expressa em g de ácido málico. $100 \mathrm{~mL}^{-1}$ de polpa (Instituto Adolfo Lutz, 2008) e a relação SS/AT.

Verificou-se a normalidade de distribuição das variáveis, por meio do teste de Lilliefors, observando-se que algumas não seguiram distribuição normal. Para procedimento de análise estatística, elas sofreram transformação dos dados $(\mathrm{x})$ por $1 / \sqrt{\mathrm{x}}$. Os dados foram submetidos à análise de variância e, as médias, comparadas entre si pela significância do teste $\mathrm{F}$, com o software estatístico ASSISTAT; exceto para a variável ciclo de produção, para a qual foram calculadas estatísticas descritivas (média, desvio padrão), encontrando-se o intervalo de $95 \%$ de confiança para as médias.

\section{RESULTADOS E DISCUSSÃO}

Verifica-se, pela Tabela 1, que o primeiro ciclo da 'Maravilha' foi 32 dias inferior ao de 'Preciosa', enquanto, no segundo ciclo, a diferença foi de 20 dias.

A redução do tempo de colheita da bananeira implica retorno mais rápido do investimento do produtor. Oliveira et al. (2007), nas condições de Visconde do Rio Branco, MG (temperatura média $(\mathrm{TM})=21,7^{\circ} \mathrm{C}$ ) e Donato et al. (2009), em Sebastião das Laranjeiras, BA $\left(\mathrm{TM}=22^{\circ} \mathrm{C}\right)$, verificaram, para 'Maravilha', período entre plantio e colheita de 476 e de 391 dias, no primeiro ciclo, e de 838 e de 599 dias, no segundo ciclo, respectivamente, ao passo que Azevedo et al. (2010), ao avaliarem o cultivar Preciosa, nas condições de Sebastião das Laranjeiras, BA, constataram 
período entre plantio e colheita de 404 e de 668 dias, no primeiro e segundo ciclo, respectivamente. Verifica-se a influência das temperaturas médias nos diferentes locais sobre os ciclos da cultura, havendo uma relação positiva entre as maiores temperaturas e a maior duração do ciclo.

A duração média do primeiro ciclo dos cultivares Maravilha e Preciosa, verificada neste trabalho, é semelhante àquela obtida por Silva et al. (2013a) para o cv. Prata Anã (347 dias), na mesma região de cultivo; no entanto, o número de dias entre o plantio e a segunda colheita da 'Prata Anã', verificado por esses autores (572 dias), foi menor que os obtidos com os cultivares estudados neste trabalho, sendo essa diferença de 53 dias para 'Preciosa' e de 32 dias para 'Maravilha', evidenciando a maior precocidade herdada de sua genitora.

Ainda na Tabela 1, estão dispostos os resultados referentes às características de plantas e de cachos das bananeiras 'Maravilha' e 'Preciosa'.

Não houve diferença significativa entre os cultivares, quando avaliado o perímetro do pseudocaule; todavia, ao avaliar a altura de plantas, pode-se observar que 'Maravilha' apresentou bananeiras com menor porte que 'Preciosa', sendo a diferença de 76 e $55 \mathrm{~cm}$, no primeiro e no segundo ciclos, respectivamente; isso, muito provavelmente, deve-se às características herdadas de suas genitoras.

Os valores de altura de plantas obtidos com 'Maravilha' foram inferiores aos encontrados por Donato et al. (2009), em Sebastião das Laranjeiras, BA (2,95 e 4,01 m no primeiro e no segundo ciclo, respectivamente), semelhantes, no entanto, aos verificados por Oliveira et al. (2007), em Visconde do Rio Branco, MG, no primeiro e segundo ciclos de produção. Para 'Preciosa', os valores de altura de plantas encontrados neste trabalho foram inferiores aos verificados por Azevedo et al. (2010), em Sebastião das Laranjeiras, BA, com o mesmo cultivar e com sua genitora, 'Pacovan', no entanto superiores àqueles verificados por Oliveira et al. (2008), em Rio Branco, AC. Essa característica está sujeita a modificações devidas às diferentes condições edafoclimáticas de cultivo, e é uma variável importante, pelo fato de interferir na definição do espaçamento e, consequentemente, na densidade de plantio, com seus reflexos na produtividade.

Na mesma região em que foi desenvolvido este trabalho, Silva et al. (2013a) obtiveram com o cv. Prata Anã altura de plantas e perímetro do pseudocaule de 2,27 $\mathrm{m}$ e $67 \mathrm{~cm}$, respectivamente, no primeiro ciclo, enquanto, no segundo ciclo, os valores obtidos foram de 3,27 m e 84 $\mathrm{cm}$, respectivamente, valores semelhantes aos obtidos neste trabalho, com o cv. Maravilha e inferiores aos obtidos com o Preciosa.

Nos dois ciclos avaliados, 'Maravilha' apresentou maior número de folhas no momento da colheita do que 'Preciosa', sendo essa superioridade de 1,8 e 1,5 folhas, no primeiro e no segundo ciclo, respectivamente. Segundo Lessa et al. (2012), plantas que retêm maior número de folhas na colheita tendem a apresentar cachos mais pesados. Lima et al. (2005) afirmam que o enchimento dos frutos está diretamente relacionado com o número de folhas adultas na colheita, entre outros fatores, um dos quais a produção de fotoassimilados. Essas afirmações corroboram os resultados deste trabalho, no qual 'Maravilha', que apresentou maior número de folhas, tanto no primeiro quanto no segundo ciclo de produção, apresentou tam-

Tabela 1: Médias do ciclo de produção (CP); altura de plantas (ALP), perímetro do pseudocaule (PPC), número de folhas vivas por planta (NFVP) na colheita, massa da matéria fresca do cacho (MFC), número de pencas (NPC) e de frutos por cacho (NFC), massa da matéria fresca (MFSP) e número de frutos da segunda penca (NFSP) de cultivares de bananeiras, cultivados no primeiro e no segundo ciclo de produção, no Submédio São Francisco. Juazeiro, BA, 2010-2011

\begin{tabular}{|c|c|c|c|c|c|c|c|c|c|c|c|}
\hline \multirow{2}{*}{ Cultivar } & \multicolumn{3}{|c|}{$C P^{2}$ (dias) } & \multicolumn{4}{|c|}{$\operatorname{ALP}(\mathbf{m})$} & \multicolumn{2}{|c|}{ PPC (cm) } & \multicolumn{2}{|c|}{ NFVP } \\
\hline & \multicolumn{2}{|c|}{$1^{\circ}$ ciclo } & $2^{\circ}$ ciclo & \multicolumn{2}{|c|}{$1^{\circ}$ ciclo } & \multicolumn{2}{|c|}{$2^{\circ}$ ciclo } & $1^{\circ}$ ciclo $^{3}$ & $2^{\circ}$ ciclo & $1^{\circ}$ ciclo & $2^{\circ}$ ciclo \\
\hline Maravilha & \multicolumn{2}{|c|}{$331,0 \pm 0,36$} & $604,7 \pm 19,94$ & \multicolumn{2}{|c|}{2,60} & \multicolumn{2}{|c|}{3,33} & 72,3 & 80,5 & 9,10 & 8,40 \\
\hline Preciosa & \multicolumn{2}{|c|}{$362,7 \pm 12,4$} & $624,7 \pm 19,21$ & \multicolumn{2}{|c|}{3,36} & \multicolumn{2}{|c|}{3,88} & 70,0 & 81,4 & 7,35 & 6,90 \\
\hline Teste $\mathrm{F}^{1}$ & \multicolumn{2}{|c|}{-} & - & \multicolumn{2}{|c|}{$91,7 * *$} & \multicolumn{2}{|c|}{$18,0 * *$} & $2,46^{\text {ns }}$ & $0,09^{\text {ns }}$ & $9,70 * *$ & $10,8 * *$ \\
\hline CV $(\%)$ & \multicolumn{2}{|c|}{3,74} & 4,69 & \multicolumn{2}{|c|}{5,93} & \multicolumn{2}{|c|}{8,14} & 2,44 & 8,31 & 15,28 & 13,36 \\
\hline \multirow{2}{*}{ Cultivar } & \multicolumn{2}{|c|}{ MFC (kg) } & \multicolumn{2}{|c|}{ NPC } & \multicolumn{3}{|c|}{ NFC } & \multicolumn{2}{|c|}{ MFSP (kg) } & \multicolumn{2}{|c|}{ NFSP } \\
\hline & $1^{\circ}$ ciclo & $\overline{2^{\circ} \text { ciclo }}$ & $1^{\circ}$ ciclo & $2^{\circ}$ ciclo & & ciclo & $2^{\circ}$ ciclo & $1^{\circ}$ ciclo & $\overline{2^{\circ} \text { ciclo }}$ & $1^{\circ}$ ciclo & $2^{\circ}$ ciclo \\
\hline Maravilha & 30,34 & 26,25 & 9,90 & 8,15 & 134 & & 107,9 & 3,53 & 3,58 & 16,15 & 14,65 \\
\hline Preciosa & 19,47 & 16,27 & 7,80 & 6,80 & 101, & & 82,8 & 2,63 & 2,64 & 14,60 & 13,4 \\
\hline Teste $\mathrm{F}^{1}$ & $63,72 * *$ & $15,0 * *$ & $49,61 * *$ & $14,7 * *$ & & $37 * *$ & $18,0 * *$ & $37,83 * *$ & $7,81 *$ & $10,59 * *$ & $2,87^{\mathrm{ns}}$ \\
\hline $\mathrm{CV}(\%)$ & 12,23 & 27,19 & 7,53 & 10,52 & 11, & & 13,87 & 10,69 & 24,32 & 6,93 & 11,76 \\
\hline
\end{tabular}

1** e *, significativo a 1 e $5 \%$ de probabilidade, respectivamente, pelo Teste F. ns Não significativo.

${ }^{2}$ Intervalo de $95 \%$ de confiança para a média.

${ }^{3}$ Dados transformados segundo $1 / \sqrt{\mathbf{x}}$. 
bém cachos mais pesados, com maiores números de pencas e de frutos por cacho (Tabela 1), bem como de frutos mais compridos (Tabela 2).

Os valores de massa da matéria fresca de cachos, verificados no cultivar Maravilha foram superiores aos de Preciosa, em 10,87 e 9,98 kg, no primeiro e no segundo ciclo, respectivamente. Essa superioridade de 'Maravilha', em relação à matéria fresca de cacho, certamente se dá pelo maior número de pencas e de frutos por cacho, apresentado pelo cultivar, e, ainda, pelo fato de as pencas apresentarem maior massa de matéria fresca e, os frutos, maior comprimento que os verificados em 'Preciosa' (Tabela 2). Lima et al. (2005) afirmam que a massa fresca de cachos depende do número de frutos por cacho e da massa dos frutos, sendo que os cultivares que apresentarem maiores valores nessas variáveis proporcionarão maior produção por cacho, havendo assim uma correlação positiva entre as variáveis. No entanto, ao avaliarem dez genótipos de bananeiras, nas condições de Cruz das Almas, BA, os autores verificaram que o número de frutos foi a variável que melhor explicou o incremento da matéria fresca de cachos.

Camolesi et al. (2012), nas condições de Assis, SP, verificaram, no primeiro ciclo de produção dos cultivares Maravilha e Preciosa, matéria fresca de cacho de 9,61 e $6,41 \mathrm{~kg}$, respectivamente, portanto inferiores às obtidas neste trabalho. Ainda no primeiro ciclo, os valores de matéria fresca de cachos de 'Maravilha' foram inferiores aos verificados por Souza et al. (2011) (32,86 kg), no entanto, semelhantes àqueles obtidos por Ramos et al. (2009) (30,2 kg), ambos em Botucatu, SP, e superiores aos verificados por Mendonça et al. (2013), em Goiânia, GO, e Fehlauer et al. (2010), em Bonito, MS (22,15 e 16,18 kg, respectivamente). Em 'Preciosa', os valores verificados neste trabalho foram superiores aos obtidos por Oliveira et al. (2008), em Rio Branco, AC, tanto no primeiro (10,73 $\mathrm{kg}$ ), quanto no segundo ciclo de produção $(10,02 \mathrm{~kg})$. Da mesma forma, as massas da matéria fresca de cachos, verificadas por Silva Júnior et al. (2012), em Vicência, PE, com o mesmo cultivar, foram inferiores, no primeiro ciclo $(14,77 \mathrm{~kg})$; por outro lado, os autores verificaram maiores médias no segundo ciclo de produção $(17,4 \mathrm{~kg})$.

'Maravilha' apresentou massa da matéria fresca do cacho superior às obtidas por Silva et al. (2013) com sua genitora, 'Prata Anã', nas mesmas condições de cultivo, tanto no primeiro, quanto no segundo ciclo, sendo as médias de 13,93 e 22,56 kg, respectivamente. Esses valores são inferiores à média obtida com 'Preciosa' no primeiro ciclo de produção deste trabalho, no entanto, superiores àquelas obtida no segundo ciclo.

Não houve diferença significativa quanto ao número de pencas por cacho, no primeiro ciclo de produção; todavia, ao avaliar essa variável no segundo ciclo, verificou-se que 'Maravilha' apresentou valores médios superiores aos de 'Preciosa'. Silva et al. (2006) apontam essa característica como fundamental para melhoristas e produtores, pois a penca está diretamente ligada à massa do cacho, que é a unidade comercial. Valores superiores de número de pencas, nos mesmos cultivares, foram verificados por Donato et al. (2009) em 'Maravilha' (média de 10 pencas por cacho), e por Azevedo et al. (2010), em 'Preciosa' (9 pencas por cacho), ambos em Sebastião das Laranjeiras, BA, no segundo ciclo de produção. Os valores verificados, neste trabalho, para 'Preciosa' no segundo ciclo, foram inferiores ainda aos de Silva Júnior et al. (2012), em Vicência, PE (7,5 pencas por cacho); no entanto, foram superiores àqueles de Oliveira et al. (2008), em Rio Branco, AC (6,08 pencas por cacho).

Tabela 2: Médias de comprimento (CF), diâmetro (DF), relação polpa/casca (RPC) e firmeza (FIR), pH, acidez titulável (AT), sólidos solúveis (SS) e relação SS/AT de frutos de cultivares de bananeiras, cultivados no primeiro e no segundo ciclo de produção, no Submédio São Francisco. Juazeiro, -BA, 2010-2011

\begin{tabular}{|c|c|c|c|c|c|c|c|c|}
\hline \multirow{2}{*}{ Cultivar } & \multicolumn{2}{|c|}{$\mathrm{CF}(\mathrm{cm})$} & \multicolumn{2}{|c|}{ DF (mm) } & \multicolumn{2}{|c|}{ RPC } & \multicolumn{2}{|c|}{$\operatorname{FIR}(\mathbf{N})$} \\
\hline & $1^{\circ}$ ciclo & $2^{\circ}$ ciclo & $1^{\circ}$ ciclo & $2^{\circ}$ ciclo & $1^{\circ}$ ciclo & $2^{\circ}$ ciclo & $1^{\circ}$ ciclo & $2^{\circ}$ ciclo \\
\hline Maravilha & 23,47 & 20,74 & 39,59 & 40,49 & 2,04 & 1,84 & 7,69 & 9,47 \\
\hline Preciosa & 18,82 & 19,18 & 38,39 & 39,42 & 2,12 & 1,50 & 8,65 & 13,15 \\
\hline Teste $\mathrm{F}^{1}$ & $18,79 * *$ & $5,06^{*}$ & $1,38^{\mathrm{ns}}$ & $0,73^{\text {ns }}$ & $0,76^{\mathrm{ns}}$ & $15,64 * *$ & $3,07^{\mathrm{ns}}$ & $80,1 * *$ \\
\hline CV (\%) & 11,35 & 7,78 & 5,84 & 8,35 & 9,64 & 11,72 & 14,91 & 8,11 \\
\hline \multirow[b]{2}{*}{ Cultivar } & \multicolumn{2}{|c|}{ pH } & \multicolumn{2}{|c|}{ SS $\left({ }^{\circ}\right.$ Brix $)$} & \multicolumn{2}{|c|}{$\mathrm{AT}(\mathrm{g} / 100 \mathrm{mg})$} & \multicolumn{2}{|c|}{ SS/AT } \\
\hline & $1^{\circ}$ ciclo & $2^{\circ}$ ciclo & $1^{\circ}$ ciclo & $2^{\circ}$ ciclo & $1^{\circ}$ ciclo & $2^{\circ}$ ciclo & $1^{\circ}$ ciclo & $2^{\circ}$ ciclo \\
\hline Maravilha & 4,64 & 4,40 & 18,85 & 19,50 & 0,75 & 0,65 & 25,48 & 31,23 \\
\hline Preciosa & 5,08 & 4,17 & 22,30 & 23,31 & 0,46 & 0,75 & 50,17 & 30,98 \\
\hline Teste $\mathrm{F}^{1}$ & $40,5 * *$ & $42,6 * *$ & $128,1 * *$ & $146,3^{* *}$ & $87,3 * *$ & $11,4 * *$ & $104,1 * *$ & $0,02^{\text {ns }}$ \\
\hline CV (\%) & 3,19 & 1,86 & 3,30 & 3,30 & 11,59 & 10,01 & 14,31 & 12,49 \\
\hline
\end{tabular}

$1 * * \mathrm{e}^{*}$, significativo a 1 e $5 \%$ de probabilidade, respectivamente, pelo Teste F. ns Não significativo. 
Quanto ao número de frutos por cacho, verifica-se que 'Maravilha' foi superior a 'Preciosa', nos dois ciclos de produção avaliados, sendo essa superioridade de 32,4 e 25,1 frutos, no primeiro e no segundo ciclo de produção, respectivamente. No primeiro ciclo de produção, Donato et al. (2009) e Ramos et al. (2009), com 'Maravilha', bem como Azevedo et al. (2010), com 'Preciosa', verificaram valores médios de 146, 167 e 105 frutos por cacho, respectivamente, superiores aos obtidos neste trabalho. No entanto, resultados inferiores foram verificados por Mendonça et al. (2013) e Fehlauer et al. (2010), com 'Maravilha' (96,66 e 115,2 frutos por cacho, respectivamente), e por Silva Júnior et al. (2012), com 'Preciosa' (87,5 frutos por cacho). No segundo ciclo de produção, Donato et al. (2009), avaliando 'Maravilha', e Azevedo et al. (2010), estudando 'Preciosa', verificaram valores médios de número de frutos por cacho superiores aos deste trabalho (170 e 124 frutos por cacho, respectivamente).

A massa da matéria fresca de penca deve estar relacionada com a massa e com o número de frutos da penca, porém, esta correlação positiva pode ser maior ou menor, a depender do genótipo e do meio ambiente (Lima Neto et al., 2003). 'Maravilha' apresentou valores médios de massa da matéria fresca da segunda penca superiores aos verificados com 'Preciosa', nos dois ciclos de produção avaliados; no entanto, quando avaliado o número de frutos da segunda penca, verificou-se que houve diferença significativa entre os cultivares apenas no primeiro ciclo de produção. As massas das matérias frescas da segunda penca de 'Maravilha', obtidas neste trabalho, foram superiores ainda às encontradas por Santos \& Carneiro (2012), em Jataí, GO, tanto no primeiro quanto no segundo ciclo de produção (1,78 e 2,88 kg, respectivamente). Todavia quando comparada a variável número de frutos da segunda penca, verifica-se que os valores encontrados no primeiro ciclo de produção deste trabalho são superiores aos daqueles autores, ocorrendo o inverso no segundo ciclo. Valores inferiores também foram encontrados por Camolesi et al. (2012), em Assis, SP, ao avaliar o número de frutos e a massa fresca da segunda penca dos cultivares Maravilha e Preciosa no primeiro ciclo de produção.

Os dados referentes às características de qualidade dos frutos das bananeiras 'Maravilha' e 'Preciosa' são mostrados na Tabela 2.

Não houve diferença significativa entre os cultivares, quando estudado o diâmetro de frutos, nos dois ciclos de produção; no entanto, quando avaliado o comprimento de frutos, verifica-se que 'Maravilha' apresentou frutos maiores que 'Preciosa', nos dois ciclos avaliados. O diâmetro de frutos, quando aliado ao seu comprimento, é utilizado para fins de classificação comercial da banana, sendo, por isso, determinante para qualidade e, consequentemente, para a remuneração do produto (Azevedo et al., 2010).

De acordo com as normas de classificação sugeridas pelo "Programa Brasileiro para a Modernização da Horticultura e Produção Integrada de Frutas" (PBMH: PIF, 2006), o agrupamento em classes garante a homogeneidade de tamanho entre frutos do mesmo lote e é determinado pelo comprimento do fruto. Os frutos de 'Preciosa', tanto no primeiro quanto no segundo ciclo de produção, classificaram-se na Classe 18 (comprimento de frutos entre 18 e $22 \mathrm{~cm}$ ), ao passo que os de 'Maravilha', nos dois ciclos avaliados, pertenceram à Classe 22 (comprimento entre 22 e $26 \mathrm{~cm}$ ). Estas normas classificam a banana por categorias, as quais descrevem a qualidade de um lote. Para cada categoria, de acordo com o grupo (Cavendish, Ouro, Maçã ou Prata), há um diâmetro (calibre) mínimo exigido por fruto. Dentro desta classificação, tanto os frutos de 'Maravilha' quanto os de 'Preciosa', nos dois ciclos, enquadraram-se na Categoria Extra, em que o diâmetro mínimo dos frutos deve ser de $34 \mathrm{~mm}$.

Não houve diferença significativa entre cultivares para relação polpa/casca, no primeiro ciclo de produção; no entanto, no segundo ciclo verificou-se, para 'Maravilha', um rendimento de polpa superior ao de 'Preciosa'. A relação polpa/casca difere bastante entre os cultivares de bananeiras. Silva et al. (2013a) relataram, para a 'Prata Anã' (AAB), valor médio de 2,44, nos dois primeiros ciclos de produção, ao passo que Silva et al. (2013b) verificaram, para a ‘Thap Maeo' (AAB), valores médios de 4,14. Jesus et al. (2004), avaliando frutos de dez genótipos de bananeiras, cultivadas no primeiro ciclo de produção, verificaram valores que variaram de 1,60 ('Pioneira' AAAB) a 4,09 ('Thap Maeo'), enquanto Cerqueira et al. (2002), avaliando 20 genótipos de bananeira, observaram valores de relação polpa/casca que variaram de 1,31 ('PV42153' - AAAB) a 3,77 ('YB42-21' - AAAB). Outro fator que influencia diretamente a relação polpa/casca é o estádio de maturação dos frutos. De acordo com Damatto Jr. et al. (2005), com o amadurecimento, os frutos passam a ter maior percentagem de polpa, uma vez que a casca desidrata mais do que a polpa nesse período. Além de perder água para a polpa, a casca da banana perde água para o meio ambiente, pela transpiração, resultando em incremento da relação polpa/casca durante o amadurecimento.

Avaliando-se a firmeza dos frutos, verificou-se que não houve diferença significativa entre os cultivares no primeiro ciclo; todavia, no segundo ciclo de produção, os frutos de 'Preciosa' apresentaram valores de firmeza superiores aos de 'Maravilha'. Incrementos nesta variável são muito importantes, a partir do estádio de colheita dos frutos e para o transporte, principalmente a longas distâncias, sendo, nesse caso, preferível que os frutos tenham maior firmeza. Segundo Pereira et al. (2004), existe 
correlação entre firmeza e resistência ao despencamento, sugerindo que frutos mais firmes são menos susceptíveis. Os valores encontrados neste trabalho, tanto com 'Maravilha', quanto com 'Preciosa', nos dois ciclos avaliados, foram superiores aos observados por Pimentel et al. (2010), ao avaliarem a firmeza de bananas 'Prata Anã' $(6,79 \mathrm{~N})$ e 'PA42-44' $(4,9 \mathrm{~N})$, na classe 6 de maturação (casca toda amarela, escala de Von Loesecke, PBMH: PIF, 2006).

Segundo Chitarra \& Chitarra (2005), os teores de sólidos solúveis (SS), a acidez titulável (AT), a relação SS/AT e o pH são atributos que melhor definem a qualidade da banana; apesar disso poucos dados são encontrados na literatura para os cultivares avaliados neste trabalho.

No primeiro ciclo de produção, 'Preciosa' apresentou $\mathrm{pH}$ de frutos mais elevado que o 'Maravilha', ocorrendo o inverso no segundo ciclo. Bezerra \& Dias (2009), avaliando sete genótipos de bananeiras, dentre elas 'Maravilha', encontraram valores de $\mathrm{pH}$ variando de 4,6 ('FHIA18 ' - AAAB) a 5,1 ('PV03-44' - AAAB), sendo que para 'Maravilha' o valor médio foi de 4,7. Esses valores são semelhantes aos verificados, neste trabalho, no primeiro ciclo de produção; no entanto, superiores àqueles do segundo ciclo dos dois cultivares estudados. Valores semelhantes aos verificados no segundo ciclo foram obtidos por Ribeiro et al. (2012), nos cultivares Maravilha $(4,30) \mathrm{e}$ Tropical - AAAB $(4,22)$.

Nos dois ciclos de produção, 'Preciosa' apresentou frutos com teores de SS superiores aos de 'Maravilha'. Os valores de SS verificados em 'Maravilha', nos dois ciclos, foram superiores aos obtidos por Ribeiro et al. (2012); no entanto, inferiores àqueles obtidos por Bezerra $\&$ Dias (2009), com o mesmo cultivar (18,51 e 22,18 ${ }^{\circ}$ Brix, respectivamente). Já os valores verificados com 'Preciosa' assemelharam-se aos de Silva et al. (2013a); Ribeiro et al. (2012), Jesus et al. (2004) e Matsuura et al. (2002), com os cultivares Prata Anã (22,76 ${ }^{\circ}$ Brix), Pacovan Ken (22,31 ${ }^{\circ}$ Brix), Pioneira (22,2 ${ }^{\circ}$ Brix) e genótipo PV03-76 (22,2 ${ }^{\circ}$ Brix), respectivamente. $\mathrm{O}$ teor de sólidos solúveis fornece um indicativo da quantidade de açúcares existentes no fruto, considerando-se que outros compostos, embora em reduzidas proporções, também possam fazer parte da constituição dos frutos, como, por exemplo, ácidos, vitaminas, aminoácidos e algumas pectinas (Kluge et al., 2002).

Avaliando-se a acidez titulável (em g de ácido málico por $100 \mathrm{ml}$ de polpa), verificou-se que no primeiro ciclo os frutos de 'Maravilha' apresentaram valores superiores aos de 'Preciosa'; todavia, ocorreu o inverso no segundo ciclo. Cerqueira et al. (2002) estudaram, em Cruz das Almas, BA, 20 genótipos de bananeiras e verificaram valores de AT variando de 0,39 (genótipo PV42-129 - AAAB) a 0,65 (genótipo PV42-85 - AAAB); Jesus et al. (2004), valores de 0,25 ('Caipira' - AAA) e 0,54 ('Pacovan' - AAB);
Matsuura et al. (2002), para 'Pacovan' e nos seus híbridos tetraploides (AAAB), PV03-44 e PV03-76, valores de 0,64, 0,53 e 0,52, respectivamente; e Silva et al. (2013a), para a 'Prata Anã', encontraram valores de 0,47 a 0,67.

De acordo com Chitarra \& Chitarra (2005), essas variações em frutos de uma mesma espécie podem ocorrer por diversos fatores, como as condições edafoclimáticas locais e as práticas culturais realizadas, bem como o estádio de maturação dos frutos.

Quanto à relação SS/AT, no primeiro ciclo de produção, os valores obtidos com 'Preciosa' foram duas vezes maiores que os de 'Maravilha'; todavia, no segundo ciclo não houve diferença significativa entre os cultivares. Essa relação tende a aumentar durante o período de maturação do fruto, por causa da diminuição dos ácidos e do aumento dos açúcares, sendo que o valor absoluto depende, dentre outros fatores, do genótipo em questão. Esta relação serve ainda como um importante indicativo de preferência do consumidor, pois, segundo Matsuura et al. (2004), os atributos de sabor são os mais importantes na escolha e compra de bananas, juntamente com a expectativa de sua vida útil de prateleira e aparência.

\section{CONCLUSÃO}

O cultivar Maravilha apresentou características de planta e de produção superiores aos do cultivar Preciosa

Quanto às características físico-químicas, 'Preciosa' apresentou frutos com maiores teores de açúcares, todavia, menores em tamanho, e, para as demais características, os dois cultivares apresentaram comportamentos semelhantes entre si no primeiro e no segundo ciclo de produção.

\section{REFERÊNCIAS}

Azevedo VF, Donato SLR, Arantes AM, Maia VM \& Silva S de O (2010) Avaliação de bananeiras tipo Prata, de porte alto, no Semiárido. Ciência e Agrotecnologia, 34:1372-1380.

Bezerra VS \& Dias JSA (2009) Avaliação físico-química de frutos de bananeiras. Acta Amazônica, 39:423-428.

Camolesi MR, Neves CSVJ, Martins NA \& Suguino E (2012) Fenologia e produtividade de cultivares de bananeiras em Assis, São Paulo. Revista Brasileira de Ciências Agrárias, 7:580-585.

Cerqueira RC, Silva S de O \& Medina VM (2002) Características pós-colheita de frutos de genótipos de bananeira (Musa spp.). Revista Brasileira de Fruticultura, 24:654-657.

Chitarra MIF \& Chitarra AB (2005) Pós-colheita de Frutos e Hortaliças: fisiologia e manuseio. $2^{\text {a }}$ ed. Lavras, Universidade Federal de Lavras. 785p.

Damatto Júnior ER, Campos AJ de, Manoel L, Moreira GC, Leonel S \& Evangelista RM (2005) Produção e caracterização de frutos de bananeira 'Prata-Anã' e 'Prata-Zulu'. Revista Brasileira de Fruticultura, 27:440-443.

Donato SRL, Arantes AM, Silva SO \& Cordeiro ZJM (2009) Comportamento fitotécnico da bananeira 'Prata Anã' e de seus híbridos. Pesquisa Agropecuária Brasileira, 44:1608-1615. 
Fehlauer TJ, Rodrigues-Otubo BM, Sandrini M \& Destro D (2010) Caracterização da produção de genótipos de banana introduzidos na região de Bonito - MS. Revista Brasileira de Fruticultura, 32:938-943.

Instituto Adolfo Lutz (2008)Conservas vegetais, frutas e produtos de frutas. In: Métodos físico-químicos para análises de alimentos. $4^{\text {a }}$ Ed. São Paulo, Instituto Adolfo Lutz. p.571-591.

Jesus SC, Folegatti MIS, Matsuura FCAU \& Cardoso RS (2004) Caracterização física e química de frutos de diferentes genótipos de bananeira. Bragantia, 63:315-323.

Kluge RA, Nachtigal JC, Fachinello JC \& Bilhalva AB (2002) Fisiologia e manejo pós-colheita de frutas de clima temperado. $2^{a}$ ed. Campinas, Livraria e Editora Ltda. 214p.

Lessa LS, Oliveira TK de, Amorim EP, Assis GML de \& Silva S de O (2012) Características vegetativas e seus efeitos sobre a produção de bananeira em três ciclos. Revista Brasileira de Fruticultura, 34:1098-1104.

Lima MB, Silva SO, Jesus ON, Oliveira WSJ, Guarrido MS \& Azevedo RL (2005) Avaliação de cultivares e híbridos de bananeira no Recôncavo baiano. Ciência e Agrotecnologia, 29:515-520.

Lima Neto FP, Silva SO, Flores JCO, Jesus ON \& Paiva LE (2003) Relações entre caracteres de rendimento e de desenvolvimento em genótipos de bananeira. Magistra, 15:275-281.

Matsuura FCAU, Cardoso RL \& Ribeiro DE (2002) Qualidade sensorial de frutos de híbridos de bananeira cultivar Pacovan. Revista Brasileira de Fruticultura, 24:263-266.

Matsuura FCAU, Costa JIP da \& Folegatti MI da S (2004) Marketing de banana: preferências do consumidor quanto aos atributos de qualidade dos frutos. Revista Brasileira de Fruticultura, 26:48-52.

Mendonça KH, Duarte DA dos S, Costa VA de M, Matos GR \& Seleguini A (2013) Avaliação de genótipos de bananeira em Goiânia, estado de Goiás. Revista Ciência Agronômica, 44:652660

Oliveira CAP, Peixoto CP, Silva SO, Ledo CAS \& Salomão LCC (2007) Genótipos de bananeira em três ciclos na Zona da Mata Mineira. Pesquisa Agropecuária Brasileira, 42:173-181.

Oliveira TK, Lessa LS, Silva SO \& Oliveira JP (2008) Características agronômicas de genótipos de bananeira em três ciclos de produção em Rio Branco-AC. Pesquisa Agropecuária Brasileira, 43:1003-1010.

PBMH: PIF - Programa Brasileiro para a Moder-nização da Horticultura: Produção Integrada de Frutas (2006) Normas de classificação de banana. São Paulo, CEAGESP. 2p.
Pereira MCT, Salomão LCC, Silva SO, Cecon PR, Puschmann R, Jesus ON \& Cerqueira RC (2004) Suscetibilidade à queda natural e caracterização dos frutos de diversos genótipos de bananeiras. Revista Brasileira de Fruticultura, 26:499-502.

Pimentel RM de A, Guimarães FN, Santos VM dos \& Resende JCF de (2010) Qualidade pós-colheita dos genótipos de banana PA42-44 e Prata-Anã cultivados no norte de Minas Gerais. Revista Brasileira de Fruticultura, 32:407-413.

Ramos DP, Leonel S, Mischan MM \& Júnior ERD (2009) Avaliação de genótipos de bananeira em Botucatu-SP. Revista Brasileira de Fruticultura, 31:1092-1101.

Ribeiro LR, Oliveira LM de, Silva S de O \& Borges AL (2012) Caracterização física e química de bananas produzidas em sistemas de cultivo convencional e orgânico. Revista Brasileira de Fruticultura, 34:774-782.

Santos SC \& Carneiro LC (2012) Desempenho de genótipos de bananeira na região de Jataí-GO. Revista Brasileira de Fruticultura, 34:783-791.

Silva Junior JF, Ledó A da S, Xavier FRS, Ferraz LGB, Ledó CA da S \& Musser R dos S (2012). Avaliação agronômica de genótipos de bananeira no Vale do Rio Siriji, Pernambuco. Revista Brasileira de Ciências Agrárias, 7:620-625.

Silva MJR da, Anjos JMC dos, Jesus PRR de, Santos GS, Lima FBF \& Ribeiro VG (2013a) Produção e caracterização da bananeira 'Prata Anã' (AAB) em dois ciclos de produção (Juazeiro, Bahia). Revista Ceres, 60:122-126.

Silva MJR da, Gomes I dos S, Souza EA de, Rios ES, Souza ARE de \& Ribeiro VG (2013b) Crescimento e produção da bananeira 'Thap Maeo' (AAB) durante dois ciclos de produção no Vale do São Francisco. Revista Ceres, 60:528-534.

Silva SO, Passos AR, Donato SLR, Salomão LCC, Pereira LV, Rodrigues MGV, Lima Neto FP \& Lima MB (2003a) Avaliação de genótipos de bananeira em diferentes ambientes. Ciência e Agrotecnologia, 27:737-748.

Silva SO, Gasparotto L, Matos AP, Cordeiro ZJM, Ferreira CF, Ramos MM \& Jesus ON (2003b) Programa de Melhoramento de Bananeira no Brasil - Resultados Recentes. Cruz das Almas, Embrapa Mandioca e Fruticultura. 36p. (Documentos, 123).

Silva SO, Pires ET, Pestana RKN, Alves JS \& Silveira DC (2006) Avaliação de clones de banana Cavendish. Ciência e Agrotecnologia, 30:832-837.

Souza ME, Leonel S \& Martin RL (2011) Caracterização do cultivar de bananeira 'Figo-Cinza' em dois ciclos de produção. Revista Brasileira de Fruticultura, 33:461-465. 